\title{
Review Article \\ Sinapic Acid and Its Derivatives as Medicine in Oxidative Stress-Induced Diseases and Aging
}

\author{
Chunye Chen \\ Key Laboratory of Biorheological Science and Technology, Ministry of Education, Bioengineering College, \\ Chongqing University, Chongqing 400030, China \\ Correspondence should be addressed to Chunye Chen; chunyech@gmail.com
}

Received 29 October 2014; Revised 2 January 2015; Accepted 12 January 2015

Academic Editor: Matías Mosqueira

Copyright (C) 2016 Chunye Chen. This is an open access article distributed under the Creative Commons Attribution License, which permits unrestricted use, distribution, and reproduction in any medium, provided the original work is properly cited.

Sinapic acid (3,5-dimethoxy-4-hydroxycinnamic acid) is an orally bioavailable phytochemical, extensively found in spices, citrus and berry fruits, vegetables, cereals, and oilseed crops and is known to exhibit antioxidant, anti-inflammatory, anticancer, antimutagenic, antiglycemic, neuroprotective, and antibacterial activities. The literature reveals that sinapic acid is a bioactive phenolic acid and has the potential to attenuate various chemically induced toxicities. This minireview is an effort to summarize the available literature about pharmacokinetic, therapeutic, and protective potential of this versatile molecule in health related areas.

\section{Introduction}

As a result of metabolic processes, there is continuous production of reactive oxygen species (ROS), such as hydroxyl radicals [1], in human body. Various biological functions like antimicrobial activity depend on ROS [2]. In normal physiological state, ROS production in body is balanced by scavengers "antioxidants." This equilibrium is disturbed in pathological conditions owing to overproduction of ROS, but comparatively low concentration of endogenous antioxidants in body. It results in the reaction between ROS and intra- and extracellular species leading to emergence of oxidative stress which causes various ailments like aging, cancer, and necrosis [3]. To tackle the oxidative stress, it is needed to restore balance between ROS and antioxidants by administering exogenous antioxidants, for example, hydroxycinnamic acids.

Hydroxycinnamic acids belong to the class of phenolic acids with bioactive carboxylic acids; the class mainly includes caffeic acid, ferulic acid, and sinapic acid $[4,5]$. According to literature, these compounds are capable of donating their phenoxyl hydrogen atom for neutralization of free radical species leading to production of corresponding phenoxyl radicals. These radicals are weekly reactive due to delocalization of unpaired electrons. Resultantly, the inhibition of dangerous radicals is useful for human health owing to antiaging potential of these phenolic acids $[6,7]$.
Sinapic acid exists in both free and ester form; some esters are sinapoyl esters, sinapine (sinapoylcholine), and sinapoyl malate $[8,9]$. Sinapic acid is a phytochemical found in various edible plants such as spices, citrus and berry fruits, vegetables [10-12], cereals, and oilseed crops [13, 14]. Sinapic acid has been tested and reported against various pathological conditions such as infections [15], oxidative stress [16], inflammation [17, 18], cancer [19], diabetes [20], neurodegeneration [21], and anxiety [22]. Some derivatives of sinapic acid, such as sinapine, 4-vinylsyringol, and syringaldehyde, have also been studied for acetylcholinesterase inhibition $[23,24]$, antimutagenicity [25], and antioxidant activity [26], respectively. 4-Vinylsyringol, a decarboxylated sinapic acid, is also termed as canolol. The term "canolol" was coined by Wakamatsu et al. due to its source, canola oil [25]. The structural formulas of sinapic acid and its derivatives are shown in Figure $1[23,27,28]$. The literature search does not show any extensive research on the biological features of sinapic acid and its derivatives. Those studies have been summarized in this brief review article so that the scientific community may pay more attention to the biological aspects of sinapic acid and its derivatives.

\section{Pharmacokinetics of Sinapic Acid}

Fruit and vegetable consumption can potentially decrease the risk of degenerative diseases which mainly attributed to 


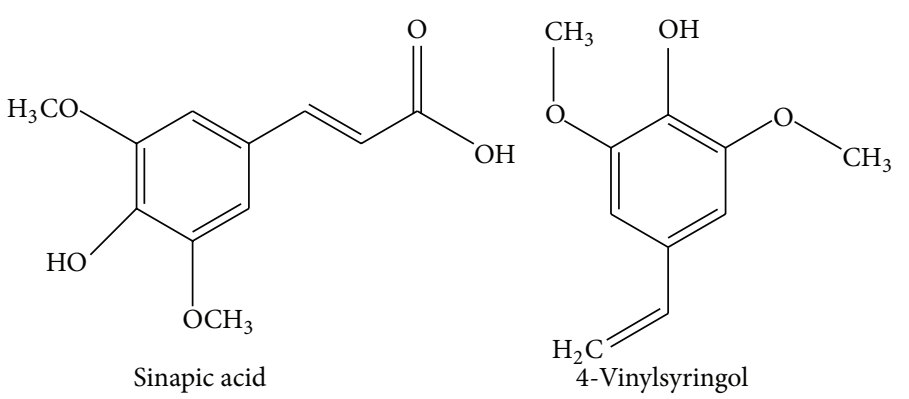<smiles>COc1cc(C=O)cc(OC)c1O</smiles>

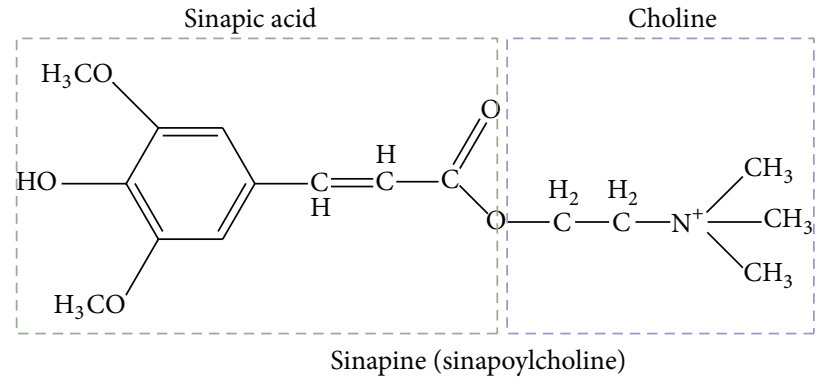

FIGURE 1: The structural formulas of sinapic acid and its derivatives (syringaldehyde, sinapine, and 4-vinylsyringol).

the phenolics present in them. Pharmacokinetic study helps to understand the role of these phenolics in human body. Serum albumin has been reported to be responsible for the transport of sinapic acid in blood due to its ability to bind with serum albumin through hydrophobic interaction and hydrogen-bonding $[29,30]$. Maximum plasma-sinapic acid level has been described as $40 \mathrm{nM}$ with a bioavailability of $3 \%$ of the total phenolics present in the nonprocessed cereal meal $[31,32]$. Moreover, the small intestine was reported as the best place for absorption of orally administered sinapic acid through active $\mathrm{Na}^{+}$gradient-driven transport [33]. Plasmasinapic acid level has also been quantified $(1.5 \mu \mathrm{g} / \mathrm{mL})$ after intake of cranberry juice in human by using GC-MS [34]. However, metabolism of sinapic acid takes place in the epithelium of the small intestine [35]; urine analysis, after sinapic acid ingestion in rats, showed the presence of sinapic acid, 3hydroxy-5-methoxyphenylpropionic acid, methyl sinapatesulfate, methyl sinapate-glucuronide, dihydrosinapic acid, 3hydroxy-5-methoxycinnamic acid, and their acid-labile conjugates [35] and these are generated by the esterase activity of the intestinal microflora $[32,36]$. Nature of these metabolites also indicates the possible metabolism of free and ester form of sinapic acid through phase I and II reactions in human small intestinal epithelium [37].

\section{Antioxidant Activity}

Reactive oxygen species (ROS) are continuously generated and are used in normal physiologically based activities [38]. Simultaneously, they are captured by different scavengers, known as antioxidants, to maintain their equilibrium in human body [39]. However, the overproduction of ROS destroys this equilibrium resulting in oxidative stress which is responsible for various pathological conditions, such as cancer, neurodegenerative disorders, and aging [40-42].
Polyphenols consist of four major classes of phytochemicals, that is, phenolic acids, flavonoids, stilbenes, and lignans [43], and behave as antioxidants, useful as anticancer, antiaging, and antimicrobial agents and scavengers of ROS produced in the body $[44,45]$. Presence of methoxy- and hydroxylgroups in the structure of polyphenols also improves their antioxidant ability $[45,46]$. Sinapic acid belongs to this family of phenolics with remarkable antioxidant potential. Various modes of antioxidant activity of sinapic acid have been documented in the literature as described below.

3.1. $\mathrm{DPPH}^{\bullet}$ Scavenging Potential. Sinapic acid is also known to show free radical scavenging ability against paramagnetic stable radical of 2,2-diphenyl-1-picrylhydrazyl (DPPH $\left.{ }^{\bullet}\right)$. According to the literature, the $\mathrm{DPPH}^{\circ}$ inhibition by $0.02 \mathrm{mM}, 0.5 \mathrm{mM}$, and $0.3 \mathrm{mM}$ of sinapic acid is $33.2 \%$ [8], $88.4 \%$ [47], and 50\% [48], respectively. Moreover, $8-8^{\prime}$-bislactone-dimer of sinapic acid also shows $\mathrm{DPPH}^{\bullet}$ scavenging activity but at concentrations higher than $200 \mu \mathrm{M}$ [48].

Additionally, sinapic acid derivatives like sinapoyl glycosides are also reported for $\mathrm{DPPH}^{*}$ scavenging activity $[49,50]$. However, these studies report the higher $\mathrm{DPPH}^{\bullet}$ radical scavenging activity of sinapic acid as compared to its glycosides including sinapoyl glucose, sinapine, and 6$\mathrm{O}$-sinapoyl sucrose except methyl 2-O-sinapoyl- $\alpha$-D-glucose and methyl 6-O-sinapoyl- $\alpha$-D-glucose which showed a little higher activity than that of sinapic acid.

Synergism in $\mathrm{DPPH}^{*}$ scavenging activity of sinapic acid is also observed; however, comparatively higher antioxidant potential of rapeseed meal and oil extracts has been reported which contains 4 -vinylsyringol $(87 \% \mathrm{w} / \mathrm{w})$ and sinapine $(13 \%$ $\mathrm{w} / \mathrm{w})$ along with sinapic acid, in comparison with pure sinapic acid alone [54]. In addition, the DPPH ${ }^{\bullet}$ scavenging activity of sinapic acid is also compared with its derivatives, for example, 4-vinylsyringol; however, $\mathrm{DPPH}^{\bullet}$ scavenging activity of 
sinapic acid (90.8\%) was described to be higher than that of 4vinylsyringol (78.7\%) at a concentration of $1 \mathrm{mg} / \mathrm{mL}$ [54-56]. Moreover, another derivative syringaldehyde is also reported to show strong $\mathrm{DPPH}^{\bullet}$ scavenging activity $[26,57]$.

3.2. $\mathrm{O}_{2}{ }^{\bullet-}$ Scavenging Potential. Superoxide anion radical $\left(\mathrm{O}_{2}{ }^{--}\right)$can suppress [4Fe-4S]-containing dehydratases and oxidize some compounds including leukoflavins, tetrahydropterins, and catecholamines. However, $\mathrm{O}_{2}{ }^{--}$scavenging activity of sinapic acid has been found similar to that of 4-vinylsyringol (decarboxylated product of sinapic acid), which shows that the decarboxylation of sinapic acid does not modify its $\mathrm{O}_{2}{ }^{--}$scavenging activity [56]. Moreover, an excellent $\mathrm{O}_{2}{ }^{\circ-}$ scavenging activity of sinapic acid (IC50 = $17.98 \mathrm{mM}$ ) has been reported in comparison with Trolox used as an antioxidant (IC50 $=7.24 \mathrm{mM}$ ) [17]. In another study, $\mathrm{O}_{2}{ }^{--}$inhibition was presented $35.52 \%$ by using $0.05 \mathrm{mM}$ of sinapic acid [58], in both enzymatic (IC50 = 70.7 $\mu \mathrm{M})$ and nonenzymatic $(\mathrm{IC} 50=979.2 \mu \mathrm{M}) \mathrm{O}_{2}{ }^{--}$generating systems. Moreover, the $\mathrm{O}_{2}{ }^{--}$scavenging activity of sinapoyl glycosides is also reported; however, this study reports the lower $\mathrm{O}_{2}{ }^{--}$ radical scavenging activity of sinapic acid (IC50 $=90 \mathrm{mM}$ ) as compared to its glycoside, 6-O-sinapoyl sucrose (IC50 = $65 \mathrm{mM})$ [59].

3.3. OH Scavenging Potential. Highly reactive hydroxyl radicals $\left({ }^{\circ} \mathrm{OH}\right)$ have potential to damage their surroundings in living system $[60,61]$. Sinapic acid has been reported as a good scavenger for ${ }^{\circ} \mathrm{OH}$ with an IC50 $=3.80 \mathrm{mM}$ where ascorbic acid was used as standard showing IC50 = $5.56 \mathrm{mM}$ [62]. Moreover, three ester derivatives of sinapic acid, methyl sinapate, $\beta$-D-(3,4-disinapoyl)fructofuranosyl$\alpha$-D-(6-sinapoyl)glucopyranoside, and 1,2-disinapoyl- $\beta$-Dglucopyranoside, have also shown comparable ${ }^{\circ} \mathrm{OH}$ scavenging activity [63].

3.4. Scavenging Potential against Other Free Radicals. Sinapic acid has been known for hydroperoxyl radical $\left({ }^{\circ} \mathrm{OOH}\right)$ scavenging activity $[64,65]$; however, 4 -vinylsyringol, a derivative of sinapic acid, scavenges the ${ }^{\circ} \mathrm{OOH}$ more quickly than sinapic acid $[65,66]$.

Sinapic acid also possesses better $\mathrm{ClO}^{-}$scavenging potential as compared to other hydroxycinnamic acids, that is, ferulic acid, chlorogenic acid, and $p$-coumaric acid. Sinapic acid has also been reported to be efficient nitric oxide radical ( NO) scavenger compared to the reference compound, that is, 2-(4-carboxyphenyl)-4,4,5,5-tetramethylimidazoline1-oxyl-3-oxide potassium salt [17].

Peroxynitrite $\left(\mathrm{ONOO}^{-}\right)$can potentially initiate apoptosis [65]. Sinapic acid has been described to perform better $\mathrm{ONOO}^{-}$scavenging activity by inhibiting 3-nitrotyrosine formation in protein (bovine serum albumin) through an electron donation mechanism as compared to standard antioxidants, that is, ascorbic acid, penicillamine, and tocopherol [65]; however, sinapic acid scavenging activity against $\mathrm{ONOO}^{-}$further increases in the presence of $25 \mathrm{mM} \mathrm{Na}_{2} \mathrm{CO}_{3}$, which contribute $\mathrm{CO}_{2}$ for simulation of physiological environment $[17,67]$. In addition, 4-vinylsyringol can also scavenge $\mathrm{ONOO}^{-}[11]$.
3.5. Suppression of Lipid Peroxidation. Lipid peroxidation generates lipid hydroperoxides, which act as a source of lipid peroxyl ( $\left.\mathrm{LOO}^{\circ}\right)$ and lipid alkoxyl $\left(\mathrm{LO}^{\circ}\right)$ radicals [68]. In a comparative study, sinapic acid was compared with $\alpha$ tocopherol and ferulic acid on the formation of hydroperoxides, and results showed that sinapic acid acts more efficiently to suppress the hydroperoxide formation by preventing the lipid oxidation in bulk methyl linoleate $[16,69]$. Moreover, in another comparative study, the antioxidant potential of sinapic acid was compared with other antioxidants, that is, Trolox and butylated hydroxyanisole [70, 71]. Sinapic acid at a concentration of $500 \mu \mathrm{mol} / \mathrm{kg}$ has been found comparable in lipid peroxidation inhibition against Trolox and butylated hydroxyanisole; the results are even better than $\alpha$-tocopherol. Similarly, the concentration-dependent inhibition of hydroperoxide formation by sinapic acid and sinapine was observed in purified rapeseed oil stored at $40^{\circ} \mathrm{C}$ in darkness; however, sinapine was found to be noneffective on hydroperoxide synthesis inhibition alone [49].

In another study, the prooxidant behavior of sinapine in rapeseed oil was reported and is attributed to its low solubility in oil [71]. An inverse relationship has been explained between the antioxidant property of sinapic acid and the concentration of tocopherols because sinapic acid may lose its function due to reaction with tocopherol radicals whose concentration got increased in elevated tocopherol level. Furthermore, an increased amount of sinapic acid is reported to produce less quantity of propanal (secondary oxidation product) at low tocopherol concentration and larger quantity at high levels. Concisely, sinapic acid can potentially play a role in the stability of oils containing small quantities of endogenous tocopherols [71].

Lipid peroxidation can be affected by sinapic acid derivatives. In a comparative study, 15\% more antioxidant activity of 4-vinylsyringol has been observed against sinapic acid in a nonpolar system; however, a diminished activity of 4 -vinylsyringol is reported in polar environment [60]. In another study, 4-vinylsyringol was found to be a more potent $\mathrm{RCOO}^{*}$ scavenger than vitamin $\mathrm{C}$ and $\alpha$-tocopherol [25]. Moreover, a promising peroxyl radical scavenging activity of syringaldehyde has been reported in crocin method, involving a competition between antioxidant and crocin to bind with the peroxyl radical; a similar antioxidant activity of syringaldehyde has been published in bulk oil and lecithin liposome [29]. Similarly, in another study, liposome (lipid membrane model) was used to assess lipid peroxidation capacity of sinapic acid and was found to be an excellent protective agent for the membrane, especially when added at the liposome synthesis stage [72]. Furthermore, linoleic acidbased lipidic model was used and the diferential scanning calorimetric analysis of sinapic acid, its alkyl esters (methyl, ethyl, propyl, and butyl sinapates), and reference antioxidant (Trolox) was conducted to compare their peroxyl radical scavenging activity. The results revealed that the test substances had reducing abilities comparable to that of reference compound suggesting sinapic acid and its alkyl esters as promising antioxidants [73]. 
(1) Inhibition of Oxidation of Low-Density Lipoprotein (LDL). Low-density lipoprotein (LDL) oxidation has been found responsible for atherosclerosis development [74]. In a comparative study, sinapic acid showed higher (28\%) antioxidant activity than 4 -vinylsyringol (7.5\%), in a LDL model system at a concentration of $10 \mu \mathrm{M}$ [54]. Moreover, peroxyl radicals produced through $\mathrm{Cu}^{+2}$-mediated oxidation of human LDL has been studied in vitro, and in terms of Trolox equivalent (TE) the following order has been observed with decreasing lipid peroxidation inhibition capacity: sinapic acid > caffeic acid > ferulic acid [75]. Additionally, concentration-dependent inhibition of LDL oxidation by sinapic acid has also been reported which can be attributed to its chelating power with $\mathrm{Cu}^{+2}$ [76-78]. Similarly, $\mathrm{Cu}^{+2}$ mediated peroxidation of human LDL and peroxyl radical can attack on erythrocyte membranes resulting in AAPH(2, $2^{\prime}$-azobis(2-amidinopropane) dihydrochloride-) induced hemolysis; however, ethyl sinapate at a concentration of $10 \mu \mathrm{M}$ was found to act more effectively (76\%) and suppressed the LDL oxidation than sinapic acid (59\%). Moreover, in terms of IC50 values, for 50\% AAPH-induced hemolysis inhibition capacity, the studied hydroxycinnamates can be configured in the following decreasing order: sinapic acid $($ IC50 $=4.5 \mu \mathrm{M})>$ ethyl sinapate $($ IC50 $=5.0 \mu \mathrm{M})>$ caffeic acid $($ IC50 $=7.2 \mu \mathrm{M})>$ ferulic acid $($ IC50 = 6.8) [79].

3.6. Anti-Inflammatory and Anticarcinogenic Properties. Nitric oxide synthase, tumor necrosis factor- $\alpha$ (TNF- $\alpha$ ), cyclooxygenase- 2 , and interleukin- $1 \beta$ are proinflammatory mediators and their expression by ROS and activated nuclear factor-kappa B (NF- $\kappa \mathrm{B})$ in macrophages cause inflammation [19]. Inflammation produced by incorrect regulation of NF- $\kappa \mathrm{B}$ disturbs immunity and can produce autoimmune diseases, that is, cancer [80]; however, a suppressive action of sinapic acid on NF- $\kappa \mathrm{B}$ has been reported in the literature $[18,81]$. Moreover, sinapic acid has been described to have time-dependent and dosedependent suppressive effect on colon and breast cancer cells (human breast cancer T47D cell line) and this inhibitory action is attributed to its antiproliferative feature $[19,82]$. Furthermore, proinflammatory mediators are reported to be suppressed by 4 -vinylsyringol [83]. In another study, sinapic acid and its alkyl esters were evaluated for anti-inflammatory activity in carrageenan-induced rat paw oedema model and an excellent anti-inflammatory activity of isopentyl sinapate was reported in comparison to other esters [84].

The ROS are generated due to Helicobacter pylori $(H$. pylori) infection, which attack and damage macromolecules, including DNA, fats, and proteins. Therefore, damaged DNA produces 8 -hydroxy-2'-deoxyguanosine (8-OHdG); however, its level can be reduced by 4 -vinylsyringol treatment [85]. In Mongolian gerbils infected with $H$. pylori, oral administration of 4 -vinylsyringol $(0.1 \%$ in the diet $)$ has been described to efficiently suppress the gastric malignancy [83]. In an in vivo study, the protective effect of canolol against inflammatory bowel disease and colitis associated carcinogenesis via inhibition of inflammatory cytokines and oxidation stress was observed [86]. Same effect of canolol has also been reported in human retinal pigment epithelium
(ARPE-19) cell line through an extracellular signal regulated kinase-mediated antioxidative pathway [87]. Additionally, canolol has also been found capable of inhibiting bacterial (H. pylori) mutation by protecting DNA damage from $\mathrm{ONOO}^{-}$, a highly oxidative chemical [88]. Peroxynitrite radicals $\left(\mathrm{ONOO}^{-}\right)$can cause DNA cleavage resulting in mutation [80]. Sinapic acid and 4-vinylsyringol have been studied for their antimutagenic characteristics and it was reported that both hydroxycinnamic acids have potential and dose-dependent antimutagenicity character, possibly through $\mathrm{ONOO}^{-}$scavenging action [25].

3.7. Anxiolytic Property. Elevated plus-maze (EPM) and holeboard test are generally used for anxiolytic studies in mice [89]. These tests were employed to study the behavior of sinapic acid and it was found that it increases the time spent in open arms significantly and also increases percentage entry in open arms [22]. Moreover, due to no side effects of sinapic acid even after its prolonged use and its selective anxiolytic features in comparison to existing anxiolytic agents [90, 91] a targeted research is required to use sinapic acid preferably in anxiety conditions.

3.8. Neuroprotective Property. Few studies are available in the literature, which elaborate the neuroprotective function of sinapic acid and its derivatives. Sinapine, a derivative of sinapic acid, during in vitro studies has been found to have dose-dependent acetylcholine (ACh) esterase inhibitory activity; moreover, sinapine and ACh both contain quaternary nitrogen to bind reversibly to specific region on AChE in a competitive mode $[23,24]$. Furthermore, activity of sinapine is more effective in the cerebral homogenate than in blood serum of rats with IC50 values of $3.66 \mu \mathrm{M}$ and $22.1 \mu \mathrm{M}$, respectively [23].

3.9. Antimicrobial Activity. Emergence of drug resistance in microbes is a fast growing issue in health sciences. Drugs available in market are constantly facing the problem of drug resistance, and therefore new drug molecules are required to counter this threat [92-94]. In in vivo studies, conducted on various Gram-positive and Gram-negative bacteria, 97-99\% eradiation of various microorganisms was observed indicating significant antibacterial potential of sinapic acid [95]. Table 1 carries minimum inhibitory concentrations (MIC) of sinapic acid against various bacterial strains observed during in vitro studies. In another study, sinapic acid was reported to have the potential to selectively kill the pathogenic bacteria leaving beneficial lactic acid bacteria alive that can resist and metabolize the sinapic acid [14]. Moreover, syringaldehyde has been described for its antifungal potential against Candida guilliermondii [96].

3.10. Antihyperglycemic Activity. Antihyperglycemic activity of sinapic acid was reported using induced-hyperglycemic in vivo model $[97,98]$ by intraperitoneal administration ( $45 \mathrm{mg} / \mathrm{kg}$ body weight) of streptozocin (STZ, a compound which destroys the insulin secreting pancreatic-cells). Subsequently, both normal and hyperglycemic rats were studied for certain biochemical markers (blood urea, serum 
TABLE 1: Minimum inhibitory concentrations (MIC) of sinapic acid against bacteria strains.

\begin{tabular}{|c|c|c|c|}
\hline Number & Reference & Bacterial strain & $\begin{array}{c}\text { Minimum } \\
\text { inhibitory } \\
\text { concentrations } \\
(\text { MIC) }\end{array}$ \\
\hline \multirow{3}{*}{1} & \multirow{3}{*}{$\begin{array}{l}\text { Barber et al., } \\
2000 \text { [51] }\end{array}$} & Bacillus subtilis & $0.45 \mathrm{~g} / \mathrm{L}$ \\
\hline & & E. coli & $0.89 \mathrm{~g} / \mathrm{L}$ \\
\hline & & $\begin{array}{c}\text { Pseudomonas } \\
\text { syringae }\end{array}$ & $1.79 \mathrm{~g} / \mathrm{L}$ \\
\hline \multirow{3}{*}{2} & \multirow{3}{*}{$\begin{array}{c}\text { Tesaki et al., } \\
1998 \text { [52] }\end{array}$} & E. coli & $0.49 \mathrm{~g} / \mathrm{L}$ \\
\hline & & $\begin{array}{c}\text { Salmonella } \\
\text { enteritidis }\end{array}$ & $0.45 \mathrm{~g} / \mathrm{L}$ \\
\hline & & $\begin{array}{c}\text { Staphylococcus } \\
\text { aureus }\end{array}$ & $0.43 \mathrm{~g} / \mathrm{L}$ \\
\hline \multirow{6}{*}{3} & \multirow{6}{*}{$\begin{array}{c}\text { Engels et al., } \\
2012 \text { [14] }\end{array}$} & Bacillus subtilis & $0.3 \mathrm{~g} / \mathrm{L}$ \\
\hline & & E. coli & $0.7 \mathrm{~g} / \mathrm{L}$ \\
\hline & & $\begin{array}{c}\text { Staphylococcus } \\
\text { aureus }\end{array}$ & $0.3 \mathrm{~g} / \mathrm{L}$ \\
\hline & & Listeria innocua & $0.3 \mathrm{~g} / \mathrm{L}$ \\
\hline & & $\begin{array}{c}\text { Listeria } \\
\text { monocytogenes }\end{array}$ & $0.2 \mathrm{~g} / \mathrm{L}$ \\
\hline & & $\begin{array}{l}\text { Pseudomonas } \\
\text { fluorescens }\end{array}$ & $0.6 \mathrm{~g} / \mathrm{L}$ \\
\hline 4 & $\begin{array}{c}\text { Johnson et } \\
\text { al., } 2008 \text { [53] }\end{array}$ & Salmonella enteric & Not mentioned \\
\hline
\end{tabular}

creatinine, uric acid, total protein, albumin, and A/G ratio) and hepato- and nephron-histopathology; however, altered values of the studied biochemical markers and pathological features came to normal state after treating the rats with sinapic acid ( $15 \mathrm{mg} / \mathrm{kg}$ and $30 \mathrm{mg} / \mathrm{kg}$ ) for 35 days; therefore, sinapic acid may have dose-dependent hepato- and nephronprotective effects in STZ-induced-hyperglycemic rats. In addition, sinapic acid can be further studied for applications in diabetic states.

3.11. Antilipidemic Activity. One of the causative agents of cardiovascular diseases, such as myocardial infarction, is abnormal lipid profile of a subject [99]. In this context, a study involving antilipidemic activity of sinapic acid has been proposed by Roy and Prince [100]. They administered isoproterenol ( $100 \mathrm{mg} / \mathrm{kg}$ body weight) to rats for inducing myocardial infarction, and then the myocardial infarcted rats (rats with raised levels of cardiac troponin-T, cholesterol, triglycerides, and free fatty acids in serum and higher STsegments in electrocardiogram) were studied to evaluate the shielding effects of sinapic acid [100, 101]. Recently, during in vivo studies performed on rats, an orally administered sinapic acid dose (12 mg/kg body weight) showed shielding effects on hypertrophy of heart, abnormal lipid levels, and electrocardiogram; furthermore, pre- and cotreatment with sinapic acid standardized the levels of myocardial infarction parameters which further elaborate antioxidant potential as well as antilipidemic activity of sinapic acid. Moreover, lysosomal dysfunction in isoproterenol-induced myocardial infarcted rats can also be cured by sinapic acid [102, 103]. These evidences elaborate the antilipidemic activity of sinapic acid.

\subsection{Toxicities and Sinapic Acid}

3.12.1. Isoproterenol-Induced Myocardial Infarction. Isoproterenol (ISO), a synthetic catecholamine, can cause the lysosomal lipid peroxidation [103] followed by the production of various lysosomal enzymes, such as lysosomal hydrolases [104], which produce myocardial infarction (MI) [105]. The ISO-mediated lysosomal dysfunction in rats suffering from MI can be overcome by oral administration of sinapic acid in rats at a concentration of $12 \mathrm{mg} / \mathrm{kg}$ body weight. This effect is evident from the changes in lysosomal lipid peroxidation, serum lysosomal enzymes, heart homogenate, lysosomal fraction, and myocardial infarct size calculated before and after simultaneous intake of sinapic acid. The treatment with sinapic acid notably suppressed the ISO-provoked release of lysosomal enzyme activity, normalized all the biochemical parameters, and diminished myocardial infarct size [102]. The membrane stabilizing features and free radical scavenging potential of sinapic acid can be the possible mode for the above-mentioned activities [104]. Thus, sinapic acid may be employed as a protective agent in MI [102].

\subsubsection{Kainic Acid-Induced Hippocampal Neuronal Damage.} Neuron depolarization and extreme calcium influx by kainic acid (KA, a nonselective agonist of AMPA and kainate receptors) generate the free radicals, activate the nitric oxide synthase (NOS), and initiate the mitochondrial dysfunctioning $[106,107]$; it results in glutamatergic activation- and oxidative stress-mediated inflammation and neurodegeneration [108, 109]. Sinapic acid has been evaluated due to its GABA receptor agonistic feature and free radical scavenging potential, during in vivo study in rats, for new glutamate receptors blockers and radical scavengers for neuroprotection. An oral administration of sinapic acid at a concentration of $10 \mathrm{mg} / \mathrm{kg}$ body weight was reported to efficiently treat the KA-induced brain damage. However, the neuroprotective effect of sinapic acid was attributed to its radical scavenging potential and anticonvulsive activity through GABA receptor activation $[110,111]$.

3.12.3. Amyloid $\beta(A \beta)_{1-42}$ Protein-Induced Alzheimer's Disease. Neuroprotective effect has been studied in mouse suffering from Alzheimer's disease, a neurological disease involving cognitive impairment $[112,113]$, and was induced in mouse by amyloid $\beta(\mathrm{A} \beta)_{1-42}$ protein injected into the hippocampus. Simultaneously, after injecting $\mathrm{A} \beta_{1-42}$ protein; an oral administration of sinapic acid was started with a dose of $10 \mathrm{mg} / \mathrm{kg}$ body weight per day. $\mathrm{A} \beta_{1-42}$ proteininduced effects were reported to be abolished by the use of sinapic acid, including elevated expression of iNOS, glial cells, and nitrotyrosine. Similarly, in rats suffering from cognitive impairment induced by scopolamine, sinapic acid shows better results [21]. Moreover, promising neuroprotective effects were reported in rodents, where sinapic acid suppressed potassium cyanide-induced hypoxia and scopolamine-induced memory impairment [114]. 
3.12.4. Carbon Tetrachloride and Dimethylnitrosamine-Induced Acute Hepatic Injury. Carbon tetrachloride $\left(\mathrm{CCl}_{4}\right)$ can produce the proinflammatory mediators causing an acute hepatic inflammation and its associated pathologies [115]. Sinapic acid has been described for its potential to revert the $\mathrm{CCl}_{4}$ intoxication of liver by oral administration of 10 or $20 \mathrm{mg} / \mathrm{kg}$ body weight in rats. Moreover, the sinapic acid treatment notably suppressed the $\mathrm{CCl}_{4}$-provoked release of proinflammatory mediators by scavenging the free radicals [116]. Sinapic acid has the potential to be used as a remedial approach for inhibiting hepatic inflammation [117-119]. Moreover, sinapic acid has also effectively treated dimethylnitrosamine-induced hepatotoxicity [120].

3.12.5. Corticosterone-Induced Toxicity. Corticosterone administration in broiler chickens can produce oxidative stress, which retards the animal growth. Corticosterone-induced toxicity can be countered by the use of 4-vinylsyringol to preserve the tissue $\alpha$-tocopherol level and to reduce the lipid peroxidation in the animal. Therefore, 4-vinylsyringol can also be added to broiler chicken feed to exert effective antioxidant effect [121].

3.12.6. tert-Butyl Hydroxide-Induced Toxicity. Antioxidant potential of 4-vinylsyringol against $t$-BH- (tert-butyl hydroxide-) mediated production of ROS, which induce the human retinal epithelial cell death, has been studied and compared to a standard antioxidant, $N$-acetyl cysteine; however, it has been reported that 4-vinylsyringol at a concentration of $200 \mu \mathrm{M}$ exerts more protective effect than the reference compound [122].

3.12.7. Arsenic-Induced Toxicity. Arsenic can cause pathological conditions like cancer and diabetes on long-term exposure $[123,124]$ by disturbing various enzymatic reactions in liver resulting in generation of ROS (superoxide, peroxyl radicals, and hydrogen peroxide) which produce hepatotoxicity. During in vivo study, arsenic-induced toxicity can be shielded by the use of sinapic acid and is mainly attributed to its metal-chelating potential [62]. Therefore, sinapic acid administration can help in avoiding arsenic-induced toxicity [125].

3.13. Toxicity Study of Sinapic Acid. The toxicity profile of sinapic acid has been reported to be considerably low in broiler chickens; no effect on the serum activity of creatine kinase and lactate dehydrogenase has been reported and observed. Therefore, it is not harmful to various body organs of the animal [126].

\section{Conclusion}

Sinapic acid and its derivatives, particularly 4-vinylsyringol, are interesting natural compounds that has potential to express various health benefits, that is, antioxidant, antiinflammatory, anticancer, antimutagenic, antiglycemic, neuroprotective, and antibacterial activities. Moreover, further extensive and targeted studies are required to explain relationship between the plasma concentrations of sinapic acid, in therapeutic dose, and the therapeutic outcomes.

\section{Conflict of Interests}

There is no conflict of interests over the contents of this paper.

\section{Acknowledgments}

This work was supported by the Key Laboratory of Biorheological Science and Technology (Chongqing University) and the General Program of National Natural Science Foundation of China [Grant no. 81202202].

\section{References}

[1] P. K. Mukherjee, N. Maity, N. K. Nema, and B. K. Sarkar, "Bioactive compounds from natural resources against skin aging," Phytomedicine, vol. 19, no. 1, pp. 64-73, 2011.

[2] G. Murtaza, S. Karim, M. R. Akram et al., "Caffeic acid phenethyl ester and therapeutic potentials," BioMed Research International, vol. 2014, Article ID 145342, 9 pages, 2014.

[3] L. H. Kligman and A. M. Kligman, "The nature of photoaging: its prevention and repair," Photodermatology, vol. 3, no. 4, pp. 215-227, 1986.

[4] N. Nićiforović and H. Abramovič, "Sinapic acid and its derivatives: natural sources and bioactivity," Comprehensive Reviews in Food Science and Food Safety, vol. 13, no. 1, pp. 34-51, 2014.

[5] M. Bunzel, J. Ralph, H. Kim et al., "Sinapate dehydrodimers and sinapate-ferulate heterodimers in cereal dietary fiber," Journal of Agricultural and Food Chemistry, vol. 51, no. 5, pp. 1427-1434, 2003.

[6] H. Kikuzaki, M. Hisamoto, K. Hirose, K. Akiyama, and H. Taniguchi, "Antioxidant properties of ferulic acid and its related compounds," Journal of Agricultural and Food Chemistry, vol. 50, no. 7, pp. 2161-2168, 2002.

[7] E. G. Bakalbassis, A. Chatzopoulou, V. S. Melissas, M. Tsimidou, M. Tsolaki, and A. Vafiadis, "Ab initio and density functional theory studies for the explanation of the antioxidant activity of certain phenolic acids," Lipids, vol. 36, no. 2, pp. 181-190, 2001.

[8] T. Sawa, T. Akaike, K. Kida, Y. Fukushima, K. Takagi, and H. Maeda, "Lipid peroxyl radicals from oxidized oils and hemeiron: implication of a high-fat diet in colon carcinogenesis," Cancer Epidemiology Biomarkers \& Prevention, vol. 7, no. 11, pp. 1007-1012, 1998.

[9] H. Maeda, T. Katsuki, T. Akaike, and R. Yasutake, "High correlation between lipid peroxide radical and tumor-promoter effect: suppression of tumor promotion in the Epstein-Barr virus/B-lymphocyte system and scavenging of alkyl peroxide radicals by various vegetable extracts," Japanese Journal of Cancer Research, vol. 83, no. 9, pp. 923-928, 1992.

[10] T. Sawa, M. Nakao, T. Akaike, K. Ono, and H. Maeda, "Alkylperoxyl radical-scavenging activity of various flavonoids and other phenolic compounds: implications for the antitumor-promoter effect of vegetables," Journal of Agricultural and Food Chemistry, vol. 47, no. 2, pp. 397-402, 1999.

[11] H. Kuwahara, A. Kanazawa, D. Wakamatu et al., "Antioxidative and antimutagenic activities of 4-vinyl-2,6-dimethoxyphenol (canolol) isolated from canola oil," Journal of Agricultural and Food Chemistry, vol. 52, no. 14, pp. 4380-4387, 2004. 
[12] D. A. Moreno, S. Pérez-Balibrea, F. Ferreres, Á. Gil-Izquierdo, and C. García-Viguera, "Acylated anthocyanins in broccoli sprouts," Food Chemistry, vol. 123, no. 2, pp. 358-363, 2010.

[13] A. Koski, S. Pekkarinen, A. Hopia, K. Wähälä, and M. Heinonen, "Processing of rapeseed oil: effects on sinapic acid derivative content and oxidative stability," European Food Research and Technology, vol. 217, no. 2, pp. 110-114, 2003.

[14] C. Engels, A. Schieber, and M. G. Gänzle, "Sinapic acid derivatives in defatted oriental mustard (Brassica juncea L.) seed meal extracts using UHPLC-DADESI-MSn and identification of compounds with antibacterial activity," European Food Research and Technology, vol. 234, no. 3, pp. 535-542, 2012.

[15] C. E. Maddox, L. M. Laur, and L. Tian, "Antibacterial activity of phenolic compounds against the phytopathogen Xylella fastidiosa," Current Microbiology, vol. 60, no. 1, pp. 53-58, 2010.

[16] H. Kikuzaki, M. Hisamoto, K. Hirose, K. Akiyama, and H. Taniguchi, "Antioxidant properties of ferulic acid and its related compounds," Journal of Agricultural and Food Chemistry, vol. 50, no. 7, pp. 2161-2168, 2002.

[17] Y. Zou, A. R. Kim, J. E. Kim, J. S. Choi, and H. Y. Chung, "Peroxynitrite scavenging activity of sinapic acid (3,5-dimethoxy-4hydroxycinnamic acid) isolated from Brassica juncea," Journal of Agricultural and Food Chemistry, vol. 50, no. 21, pp. 5884-5890, 2002.

[18] K.-J. Yun, D.-J. Koh, S.-H. Kim et al., "Anti-inflammatory effects of sinapic acid through the suppression of inducible nitric oxide synthase, cyclooxygase- 2 , and proinflammatory cytokines expressions via nuclear factor- $\kappa \mathrm{B}$ inactivation," Journal of Agricultural and Food Chemistry, vol. 56, no. 21, pp. 1026510272, 2008.

[19] E. A. Hudson, P. A. Dinh, T. Kokubun, M. S. J. Simmonds, and A. Gescher, "Characterization of potentially chemopreventive phenols in extracts of brown rice that inhibit the growth of human breast and colon cancer cells," Cancer Epidemiology Biomarkers and Prevention, vol. 9, no. 11, pp. 1163-1170, 2000.

[20] G. Kanchana, W. J. Shyni, M. Rajadurai, and R. Periasamy, "Evaluation of antihyperglycemic effect of sinapic acid in normal and streptozotocin-induced diabetes in albino rats," Global Journal of Pharmacology, vol. 5, no. 1, pp. 33-39, 2011.

[21] X. L. Sun, H. Ito, T. Masuoka, C. Kamei, and T. Hatano, "Effect of Polygala tenuifolia root extract on scopolamine-induced impairment of rat spatial cognition in an eight-arm radial maze task," Biological and Pharmaceutical Bulletin, vol. 30, no. 9, pp. 1727-1731, 2007.

[22] B. H. Yoon, J. W. Jung, J. J. Lee et al., "Anxiolytic-like effects of sinapic acid in mice," Life Sciences, vol. 81, no. 3, pp. 234-240, 2007.

[23] L. He, H.-T. Li, S.-W. Guo et al., "Inhibitory effects of sinapine on activity of acetylcholinesterase in cerebral homogenate and blood serum of rats," Zhongguo Zhongyao Zazhi, vol. 33, no. 7, pp. 813-815, 2008.

[24] F. Ferreres, F. Fernandes, C. Sousa, P. Valentão, J. A. Pereira, and P. B. Andrade, "Metabolic and bioactivity insights into Brassica oleracea var. acephala," Journal of Agricultural and Food Chemistry, vol. 57, no. 19, pp. 8884-8892, 2009.

[25] D. Wakamatsu, S. Morimura, T. Sawa, K. Kida, C. Nakai, and H. Maeda, "Isolation, identification, and structure of a potent alkyl-peroxyl radical scavenger in crude canola oil, canolol," Bioscience, Biotechnology, and Biochemistry, vol. 69, no. 8, pp. 1568-1574, 2005.

[26] H. Kuwahara, A. Kanazawa, D. Wakamatu et al., "Antioxidative and antimutagenic activities of 4-vinyl-2,6-dimethoxyphenol (canolol) isolated from canola oil," Journal of Agricultural and Food Chemistry, vol. 52, no. 14, pp. 4380-4387, 2004.

[27] R. Bortolomeazzi, N. Sebastianutto, R. Toniolo, and A. Pizzariello, "Comparative evaluation of the antioxidant capacity of smoke flavouring phenols by crocin bleaching inhibition, DPPH radical scavenging and oxidation potential," Food Chemistry, vol. 100, no. 4, pp. 1481-1489, 2007.

[28] L. Z. Lin and J. M. Harnly, "Phenolic component profiles of mustard greens, Yu Choy, and 15 other Brassica vegetables," Journal of Agricultural and Food Chemistry, vol. 58, no. 11, pp. 6850-6857, 2010.

[29] O. G. Bountagkidou, S. A. Ordoudi, and M. Z. Tsimidou, "Structure-antioxidant activity relationship study of natural hydroxybenzaldehydes using in vitro assays," Food Research International, vol. 43, no. 8, pp. 2014-2019, 2010.

[30] L. Trnková, I. Boušová, L. Ryšánková, P. Vrabcová, and J. Dršata, "Antioxidants and environmental stress: spectroscopic study on stability of natural compounds and their interaction with a molecule of protein in an invitro model," Proceedings of Ecopole, vol. 3, no. 1, pp. 27-34, 2009.

[31] L. Trnková, I. Boušová, V. Kubíček, and J. Dršata, "Binding of naturally occurring hydroxycinnamic acids to bovine serum albumin," Natural Science, vol. 2, pp. 563-570, 2010.

[32] S. M. Kern, R. N. Bennett, F. A. Mellon, P. A. Kroon, and M.-T. Garcia-Conesa, "Absorption of hydroxycinnamates in humans after high-bran cereal consumption," Journal of Agricultural and Food Chemistry, vol. 51, no. 20, pp. 6050-6055, 2003.

[33] P. Ader, B. Grenacher, P. Langguth, E. Scharrer, and S. Wolffram, "Cinnamate uptake by rat small intestine: transport kinetics and transepithelial transfer," Experimental Physiology, vol. 81, no. 6, pp. 943-955, 1996.

[34] K. Zhang and Y. Zuo, "GC-MS determination of flavonoids and phenolic and benzoic acids in human plasma after consumption of cranberry juice," Journal of Agricultural and Food Chemistry, vol. 52, no. 2, pp. 222-227, 2004.

[35] L. A. Griffiths, "Metabolism of sinapic acid and related compounds in the rat," Biochemical Journal, vol. 113, no. 4, pp. 603609, 1969.

[36] A. R. Rechner, G. Kuhnle, H. Hu et al., "The metabolism of dietary polyphenols and the relevance to circulating levels of conjugated metabolites," Free Radical Research, vol. 36, no. 11, pp. 1229-1241, 2002.

[37] J.-F. Cavin, L. Barthelmebs, J. Guzzo et al., "Purification and characterization of an inducible p-coumaric acid decarboxylase from Lactobacillus plantarum," FEMS Microbiology Letters, vol. 147, no. 2, pp. 291-295, 1997.

[38] M. Valko, D. Leibfritz, J. Moncol, M. T. D. Cronin, M. Mazur, and J. Telser, "Free radicals and antioxidants in normal physiological functions and human disease," International Journal of Biochemistry and Cell Biology, vol. 39, no. 1, pp. 44-84, 2007.

[39] B. Halliwell and J. M. C. Gutteridge, Free Radicals in Biology and Medicine, Clarendon Press, Oxford, UK, 1989.

[40] F. Wang and J. Yang, "A comparative study of caffeic acid and a novel caffeic acid conjugate SMND-309 on antioxidant properties in vitro," LWT-Food Science and Technology, vol. 46, no. 1, pp. 239-244, 2012.

[41] E. H. Sarsour, M. G. Kumar, L. Chaudhuri, A. L. Kalen, and P. C. Goswami, "Redox control of the cell cycle in health and disease," Antioxidants and Redox Signaling, vol. 11, no. 12, pp. 2985-3011, 2009. 
[42] B. Uttara, A. V. Singh, P. Zamboni, and R. T. Mahajan, "Oxidative stress and neurodegenerative diseases: a review of upstream and downstream antioxidant therapeutic options," Current Neuropharmacology, vol. 7, no. 1, pp. 65-74, 2009.

[43] K. B. Pandey and S. I. Rizvi, "Plant polyphenols as dietary antioxidants in human health and disease," Oxidative Medicine and Cellular Longevity, vol. 2, no. 5, pp. 270-278, 2009.

[44] K. R. Martin and C. L. Appel, "Polyphenols as dietary supplements: a double-edged sword," Nutrition and Dietary Supplements, vol. 2, pp. 1-12, 2010.

[45] K. H. Janbaz, S. A. Saeed, and A. H. Gilani, "Studies on the protective effects of caffeic acid and quercetin on chemicalinduced hepatotoxicity in rodents," Phytomedicine, vol. 11, no. 5, pp. 424-430, 2004.

[46] C. A. Rice-Evans, N. J. Miller, and G. Paganga, "Structureantioxidant activity relationships of flavonoids and phenolic acids," Free Radical Biology and Medicine, vol. 20, no. 7, pp. 933956, 1996.

[47] N. Nenadis and M. Tsimidou, "Observations on the estimation of scavenging activity of phenolic compounds using rapid 1,1-diphenyl-2-picrylhydrazyl (DPPH.) Tests," Journal of the American Oil Chemists' Society, vol. 79, no. 12, pp. 1191-1195, 2002.

[48] H. Hotta, S. Nagano, M. Ueda, Y. Tsujino, J. Koyama, and T. Osakai, "Higher radical scavenging activities of polyphenolic antioxidants can be ascribed to chemical reactions following their oxidation," Biochimica et Biophysica Acta: General Subjects, vol. 1572, no. 1, pp. 123-132, 2002.

[49] U. Thiyam, H. Stöckmann, T. Z. Felde, and K. Schwarz, "Antioxidative effect of the main sinapic acid derivatives from rapeseed and mustard oil by-products," European Journal of Lipid Science and Technology, vol. 108, no. 3, pp. 239-248, 2006.

[50] P. Kylli, P. Nousiainen, P. Biely, J. Sipilä, M. Tenkanen, and M. Heinonen, "Antioxidant potential of hydroxycinnamic acid glycoside esters," Journal of Agricultural and Food Chemistry, vol. 56, no. 12, pp. 4797-4805, 2008.

[51] M. S. Barber, V. S. McConnell, and B. S. Decaux, "Antimicrobial intermediates of the general phenylpropanoid and lignin specific pathways," Phytochemistry, vol. 54, no. 1, pp. 53-56, 2000.

[52] S. Tesaki, S. Tanabe, H. Ono, E. Fukushi, J. Kawabata, and M. Watanabe, "4-hydroxy-3-nitrophenyllactic and sinapic acids as antibacterial compounds from mustard seeds," Bioscience, Biotechnology and Biochemistry, vol. 62, no. 5, pp. 998-1000, 1998.

[53] M. L. Johnson, J. P. Dahiya, A. A. Olkowski, and H. L. Classen, "The effect of dietary sinapic acid (4-hydroxy-3, 5-dimethoxycinnamic acid) on gastrointestinal tract microbial fermentation, nutrient utilization, and egg quality in laying hens," Poultry Science, vol. 87, no. 5, pp. 958-963, 2008.

[54] S. Vuorela, K. Kreander, M. Karonen et al., "Preclinical evaluation of rapeseed, raspberry, and pine bark phenolics for health related effects," Journal of Agricultural and Food Chemistry, vol. 53, no. 15, pp. 5922-5931, 2005.

[55] B. Harbaum-Piayda, K. Oehlke, F. D. Sönnichsen, P. Zacchi, R. Eggers, and K. Schwarz, "New polyphenolic compounds in commercial deodistillate and rapeseed oils," Food Chemistry, vol. 123, no. 3, pp. 607-615, 2010.

[56] P. Terpinc, T. Polak, N. Šegatin, A. Hanzlowsky, N. P. Ulrih, and H. Abramovič, "Antioxidant properties of 4-vinyl derivatives of hydroxycinnamic acids," Food Chemistry, vol. 128, no. 1, pp. 6269, 2011.
[57] C. Ao, A. Li, A. A. Elzaawely, T. D. Xuan, and S. Tawata, "Evaluation of antioxidant and antibacterial activities of Ficus microcarpa L. fil. extract," Food Control, vol. 19, no. 10, pp. 940$948,2008$.

[58] A. M. Jalaludeen and L. Pari, "Studies on the antioxidant and free radical-scavenging effect of sinapic acid: an in vivo and in vitro model," Journal of Pharmaceutical Sciences and Research, vol. 3, no. 9, pp. 1447-1455, 2011.

[59] N. Fabre, P. Urizzi, J. P. Souchard et al., "An antioxidant sinapic acid ester isolated from Iberis amara," Fitoterapia, vol. 71, no. 4, pp. 425-428, 2000.

[60] J. M. C. Gutteridge and B. Halliwell, "The deoxyribose assay: an assay both for 'free' hydroxyl radical and for site-specific hydroxyl radical production," Biochemical Journal, vol. 253, no. 3, pp. 932-933, 1988.

[61] J. Nordberg and E. S. J. Arnér, "Reactive oxygen species, antioxidants, and the mammalian thioredoxin system," Free Radical Biology \& Medicine, vol. 31, no. 11, pp. 1287-1312, 2001.

[62] L. Pari and A. Mohamed Jalaludeen, "Protective role of sinapic acid against arsenic - induced toxicity in rats," ChemicoBiological Interactions, vol. 194, no. 1, pp. 40-47, 2011.

[63] Y. Takaya, Y. Kondo, T. Furukawa, and M. Niwa, "Antioxidant constituents of radish sprout (Kaiware-daikon), Raphanus sativus L.," Journal of Agricultural and Food Chemistry, vol. 51, no. 27, pp. 8061-8066, 2003.

[64] A. Galano, M. Francisco-Márquez, and J. R. Alvarez-Idaboy, "Mechanism and kinetics studies on the antioxidant activity of sinapinic acid," Physical Chemistry Chemical Physics, vol. 13, no. 23, pp. 11199-11205, 2011.

[65] T. Niwa, U. Doi, Y. Kato, and T. Osawa, "Inhibitory mechanism of sinapinic acid against peroxynitrite-mediated tyrosine nitration of protein in vitro," FEBS Letters, vol. 459, no. 1, pp. 43-46, 1999.

[66] A. Galano, M. Francisco-Márquez, and J. R. Alvarez-Idaboy, "Canolol: a promising chemical agent against oxidative stress," The Journal of Physical Chemistry B, vol. 115, no. 26, pp. 85908596, 2011.

[67] S. Akhter, J. R. Green, P. Root, G. J. Thatcher, and B. Mutus, "Peroxynitrite and $\mathrm{NO}^{+}$donors form colored nitrite adducts with sinapinic acid: potential applications," Nitric Oxide, vol. 8, no. 4, pp. 214-221, 2003.

[68] H. Esterbauer, F. Muskiet, and D. F. Horrobin, "Cytotoxicity and genotoxicity of lipid-oxidation products," The American Journal of Clinical Nutrition, vol. 57, supplement 5, pp. 779S-786S, 1993.

[69] S. S. Pekkarinen, H. Stöckmann, K. Schwarz, I. M. Heinonen, and A. I. Hopia, "Antioxidant activity and partitioning of phenolic acids in bulk and emulsified methyl linoleate," Journal of Agricultural and Food Chemistry, vol. 47, no. 8, pp. 3036-3043, 1999.

[70] U. Thiyam, A. Kuhlmann, H. Stöckmann, and K. Schwarz, "Prospects of rapeseed oil by-products with respect to antioxidative potential," Comptes Rendus Chimie, vol. 7, no. 6-7, pp. 611-616, 2004.

[71] U. Thiyam, H. Stöckmann, and K. Schwarz, "Antioxidant activity of rapeseed phenolics and their interactions with tocopherols during lipid oxidation," Journal of the American Oil Chemists' Society, vol. 83, no. 6, pp. 523-528, 2006.

[72] J. Zhang, R. A. Stanley, and L. D. Melton, "Lipid peroxidation inhibition capacity assay for antioxidants based on liposomal membranes," Molecular Nutrition and Food Research, vol. 50, no. 8, pp. 714-724, 2006. 
[73] A. Gaspar, M. Martins, P. Silva et al., "Dietary phenolic acids and derivatives. Evaluation of the antioxidant activity of sinapic acid and its alkyl esters," Journal of Agricultural and Food Chemistry, vol. 58, no. 21, pp. 11273-11280, 2010.

[74] R. Stocker and J. F. Keaney Jr., "Role of oxidative modifications in atherosclerosis," Physiological Reviews, vol. 84, no. 4, pp. 13811478, 2004.

[75] F. Natella, M. Nardini, M. Di Felice, and C. Scaccini, "Benzoic and cinnamic acid derivatives as antioxidants: structure-activity relation," Journal of Agricultural and Food Chemistry, vol. 47, no. 4, pp. 1453-1459, 1999.

[76] M. F. Andreasen, A.-K. Landbo, L. P. Christensen, A. Hansen, and A. S. Meyer, "Antioxidant effects of phenolic rye (Secale cereale L.) extracts, monomeric hydroxycinnamates, and ferulic acid dehydrodimers on human low-density lipoproteins," Journal of Agricultural and Food Chemistry, vol. 49, no. 8, pp. 40904096, 2001.

[77] M. Nardini, M. D’Aquino, G. Tomassi, V. Gentili, M. Di Felice, and C. Scaccini, "Inhibition of human low-density lipoprotein oxidation by caffeic acid and other hydroxycinnamic acid derivatives," Free Radical Biology and Medicine, vol. 19, no. 5, pp. 541-552, 1995.

[78] M. J. Hynes and M. O. Coinceanainn, "Investigation of the release of iron from ferritin by naturally occurring antioxidants," Journal of Inorganic Biochemistry, vol. 90, no. 1-2, pp. 1821, 2002.

[79] J. Chalas, C. Claise, M. Edeas et al., "Effect of ethyl esterification of phenolic acids on low-density lipoprotein oxidation," Biomedicine and Pharmacotherapy, vol. 55, no. 1, pp. 54-60, 2001.

[80] L. Connelly, W. Barham, H. M. Onishko et al., "NF-kappaB activation within macrophages leads to an anti-tumor phenotype in a mammary tumor lung metastasis model," Breast Cancer Research, vol. 13, no. 4, article R83, 2011.

[81] Y. Shukla and R. Singh, "Resveratrol and cellular mechanisms of cancer prevention," Annals of the New York Academy of Sciences, vol. 1215, no. 1, pp. 1-8, 2011.

[82] M. Kampa, V.-I. Alexaki, G. Notas et al., "Antiproliferative and apoptotic effects of selective phenolic acids on T47D human breast cancer cells: potential mechanisms of action," Breast Cancer Research, vol. 6, no. 2, pp. R63-R74, 2004.

[83] X. Cao, T. Tsukamoto, T. Seki et al., "4-Vinyl-2,6-dimethoxyphenol (canolol) suppresses oxidative stress and gastric carcinogenesis in Helicobacter pylori-infected carcinogen-treated Mongolian gerbils," International Journal of Cancer, vol. 122, no. 7, pp. 1445-1454, 2008.

[84] A. S. Chawla, M. Singh, D. Kumar, and M. Kumar, "Antiinflammatory action of sinapic and its esters in carrageenaninduced rat paw oedema model," Indian Journal of Pharmaceutical Sciences, vol. 55, no. 5, pp. 184-187, 1993.

[85] Y. Q. Sun, I. Girgensone, P. Leanderson, F. Petersson, and K. Borch, "Effects of antioxidant vitamin supplements on Helicobacter pylori-induced gastritis in Mongolian gerbils," Helicobacter, vol. 10, no. 1, pp. 33-42, 2005.

[86] J. Fang, T. Seki, T. Tsukamoto et al., "Protection from inflammatory bowel disease and colitis-associated carcinogenesis with 4-vinyl-2,6-dimethoxyphenol (canolol) involves suppression of oxidative stress and inflammatory cytokines," Carcinogenesis, vol. 34, no. 12, pp. 2833-2841, 2013.

[87] X. Dong, Z. Li, W. Wang et al., "Protective effect of canolol from oxidative stress-induced cell damage in ARPE-19 cells via an
ERK mediated antioxidative pathway," Molecular Vision, vol. 17, pp. 2040-2048, 2011.

[88] H. Kuwahara, T. Kariu, J. Fang, and H. Maeda, "Generation of drug-resistant mutants of Helicobacter pylori in the presence of peroxynitrite, a derivative of nitric oxide, at pathophysiological concentration," Microbiology and Immunology, vol. 53, no. 1, pp. $1-7,2009$.

[89] J. W. Jung, N. Y. Ahn, H. R. Oh et al., "Anxiolytic effects of the aqueous extract of Uncaria rhynchophylla," Journal of Ethnopharmacology, vol. 108, no. 2, pp. 193-197, 2006.

[90] J. J. Lee, E. T. Hahm, B. I. Min, S. H. Han, J. J. Cho, and Y. W. Cho, "Roles of protein kinase $\mathrm{A}$ and $\mathrm{C}$ in the opioid potentiation of the GABAA response in rat periaqueductal gray neuron," Neuropharmacology, vol. 44, no. 5, pp. 573-583, 2003.

[91] M. Lader and S. Morton, "Benzodiazepine problems," British Journal of Addiction, vol. 86, no. 7, pp. 823-828, 1991.

[92] M. M. Cowan, "Plant products as antimicrobial agents," Clinical Microbiology Reviews, vol. 12, no. 4, pp. 564-582, 1999.

[93] S. Gibbons, "Plants as a source of bacterial resistance modulators and anti-infective agents," Phytochemistry Reviews, vol. 4, no. 1, pp. 63-78, 2005.

[94] M. Saleem, M. Nazir, M. S. Ali et al., "Antimicrobial natural products: an update on future antibiotic drug candidates," Natural Product Reports, vol. 27, no. 2, pp. 238-254, 2010.

[95] H. Nowak, K. Kujawa, R. Zadernowski, B. Roczniak, and H. KozŁowska, "Antioxidative and bactericidal properties of phenolic compounds in rapeseeds," European Journal of Lipid Science and Technology, vol. 94, no. 4, pp. 149-152, 1992.

[96] C. Kelly, O. Jones, C. Barnhart, and C. Lajoie, "Effect of furfural, vanillin and syringaldehyde on Candida guilliermondii growth and xylitol biosynthesis," in Biotechnology for Fuels and Chemicals, W. S. Adney, J. D. McMillan, J. Mielenz, and K. T. Klasson, Eds., pp. 615-626, Humana Press, New York, NY, USA, 2008.

[97] J. S. Wilson, K. Ganesan, and M. Palanisamy, "Effect of sinapic acid on biochemical markers and histopathological studies in normal and streptozotocin-induced diabetes in wistar rats," International Journal of Pharmacy and Pharmaceutical Sciences, vol. 3, no. 4, pp. 115-120, 2011.

[98] Y.-G. Cherng, C.-C. Tsai, H.-H. Chung, Y.-W. Lai, S.-C. Kuo, and J.-T. Cheng, "Antihyperglycemic action of sinapic acid in diabetic rats," Journal of Agricultural and Food Chemistry, vol. 61, no. 49, pp. 12053-12059, 2013.

[99] J. Wang, H. Bo, X. Meng, Y. Wu, Y. Bao, and Y. Li, "A simple and fast experimental model of myocardial infarction in the mouse," Texas Heart Institute Journal, vol. 33, no. 3, pp. 290-293, 2006.

[100] S. J. Roy and P. S. M. Prince, "Protective effects of sinapic acid on cardiac hypertrophy, dyslipidaemia and altered electrocardiogram in isoproterenol-induced myocardial infarcted rats," European Journal of Pharmacology, vol. 699, no. 1-3, pp. 213-218, 2013.

[101] P. S. M. Prince, "A biochemical, electrocardiographic, electrophoretic, histopathological and in vitro study on the protective effects of (-)epicatechin in isoproterenol-induced myocardial infarcted rats," European Journal of Pharmacology, vol. 671, no. 1-3, pp. 95-101, 2011.

[102] S. J. Roy and S. M. P. Prince, "Protective effects of sinapic acid on lysosomal dysfunction in isoproterenol induced myocardial infarcted rats," Food and Chemical Toxicology, vol. 50, no. 11, pp. 3984-3989, 2012. 
[103] X. Zeng, J. Zheng, C. Fu et al., "A newly synthesized sinapic acid derivative inhibits endothelial activation in vitro and in vivo," Molecular Pharmacology, vol. 83, no. 5, pp. 1099-1108, 2013.

[104] P. S. M. Prince, H. Priscilla, and P. T. Devika, "Gallic acid prevents lysosomal damage in isoproterenol induced cardiotoxicity in Wistar rats," European Journal of Pharmacology, vol. 615, no. 1-3, pp. 139-143, 2009.

[105] M. M. Kannan and S. D. Quine, "Ellagic acid ameliorates isoproterenol induced oxidative stress: evidence from electrocardiological, biochemical and histological study," European Journal of Pharmacology, vol. 659, no. 1, pp. 45-52, 2011.

[106] S.-Y. Chung and S.-H. Han, "Melatonin attenuates kainic acidinduced hippocampal neurodegeneration and oxidative stress through microglial inhibition," Journal of Pineal Research, vol. 34, no. 2, pp. 95-102, 2003.

[107] K. A. Lehtimäki, J. Peltola, E. Koskikallio, T. Keränen, and J. Honkaniemi, "Expression of cytokines and cytokine receptors in the rat brain after kainic acid-induced seizures," Molecular Brain Research, vol. 110, no. 2, pp. 253-260, 2003.

[108] L. A. Izquierdo, D. M. Barros, P. G. Ardenghi et al., "Different hippocampal molecular requirements for short- and long-term retrieval of one-trial avoidance learning," Behavioural Brain Research, vol. 111, no. 1-2, pp. 93-98, 2000.

[109] S. Zagulska-Szymczak, R. K. Filipkowski, and L. Kaczmarek, "Kainate-induced genes in the hippocampus: lessons from expression patterns," Neurochemistry International, vol. 38, no. 6, pp. 485-501, 2001.

[110] N. M. Anson, A.-M. Aura, E. Selinheimo et al., "Bioprocessing of wheat bran in whole wheat bread increases the bioavailability of phenolic acids in men and exerts antiinflammatory effects ex vivo1-3," Journal of Nutrition, vol. 141, no. 1, pp. 137-143, 2011.

[111] D. H. Kim, B. H. Yoon, W. Y. Jung et al., "Sinapic acid attenuates kainic acid-induced hippocampal neuronal damage in mice," Neuropharmacology, vol. 59, no. 1-2, pp. 20-30, 2010.

[112] H. E. Lee, D. H. Kim, S. J. Park et al., "Neuroprotective effect of sinapic acid in a mouse model of amyloid $\beta_{1-42}$ protein-induced Alzheimer's disease," Pharmacology Biochemistry and Behavior, vol. 103, no. 2, pp. 260-266, 2012.

[113] S. Craft, "The role of metabolic disorders in Alzheimer disease and vascular dementia: two roads converged," Archives of Neurology, vol. 66, no. 3, pp. 300-305, 2009.

[114] F. Karakida, Y. Ikeya, M. Tsunakawa et al., "Cerebral protective and cognition-improving effects of sinapic acid in rodents," Biological and Pharmaceutical Bulletin, vol. 30, no. 3, pp. 514519, 2007.

[115] J. George, K. R. Rao, R. Stern, and G. Chandrakasan, "Dimethylnitrosamine-induced liver injury in rats: the early deposition of collagen," Toxicology, vol. 156, no. 2-3, pp. 129-138, 2001.

[116] G. Poli, "Liver damage due to free radicals," British Medical Bulletin, vol. 49, no. 3, pp. 604-620, 1993.

[117] D.-S. Shin, K. W. Kim, H. Y. Chung, S. Yoon, and J.-O. Moon, "Effect of sinapic acid against carbon tetrachloride-induced acute hepatic injury in rats," Archives of Pharmacal Research, vol. 36, no. 5, pp. 626-633, 2013.

[118] D.-S. Shin, K. W. Kim, H. Y. Chung, S. Yoon, and J.-O. Moon, "Effect of sinapic acid against dimethylnitrosamine-induced hepatic fibrosis in rats," Archives of Pharmacal Research, vol. 36, no. 5, pp. 608-618, 2013.

[119] K. Reyes-Gordillo, J. Segovia, M. Shibayama, P. Vergara, M. G. Moreno, and P. Muriel, "Curcumin protects against acute liver damage in the rat by inhibiting NF- $\kappa \mathrm{B}$, proinflammatory cytokines production and oxidative stress," Biochimica et Biophysica Acta-General Subjects, vol. 1770, no. 6, pp. 989-996, 2007.

[120] L. W. D. Weber, M. Boll, and A. Stampfl, "Hepatotoxicity and mechanism of action of haloalkanes: carbon tetrachloride as a toxicological model," Critical Reviews in Toxicology, vol. 33, no. 2, pp. 105-136, 2003.

[121] Y. Z. Eid, "Novel antioxidant canolol reduces glucocorticoid induced oxidative stress in broiler chickens," Egyptian Poultry Science, vol. 30, pp. 917-926, 2010.

[122] X. Dong, Z. Li, W. Wang, W. Zhang, S. Liu, and X. Zhang, "Protective effect of canolol from oxidative stress-induced cell damage in ARPE-19 cells via an ERK mediated antioxidative pathway," Molecular Vision, vol. 17, pp. 2040-2048, 2011.

[123] H. Shi, X. Shi, and K. J. Liu, "Oxidative mechanism of arsenic toxicity and carcinogenesis," Molecular and Cellular Biochemistry, vol. 255, no. 1-2, pp. 67-78, 2004.

[124] J. Brinkel, M. H. Khan, and A. Kraemer, "A systematic review of arsenic exposure and its social and mental health effects with special reference to Bangladesh," International Journal of Environmental Research and Public Health, vol. 6, no. 5, pp. 1609-1619, 2009.

[125] F. Shahidi and M. Naczk, Phenolics in Food and Nutraceuticals, CRC Press, Boca Raton, Fla, USA, 2004.

[126] H. Y. Qiao, J. P. Dahiya, and H. L. Classen, "Nutritional and physiological effects of dietary sinapic acid (4-hydroxy3,5-dimethoxy-cinnamic acid) in broiler chickens and its metabolism in the digestive tract," Poultry Science, vol. 87, no. 4, pp. 719-726, 2008. 


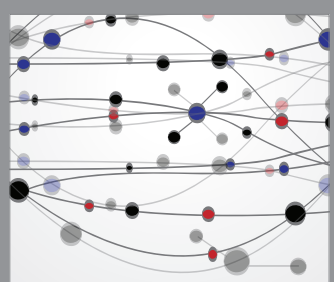

The Scientific World Journal
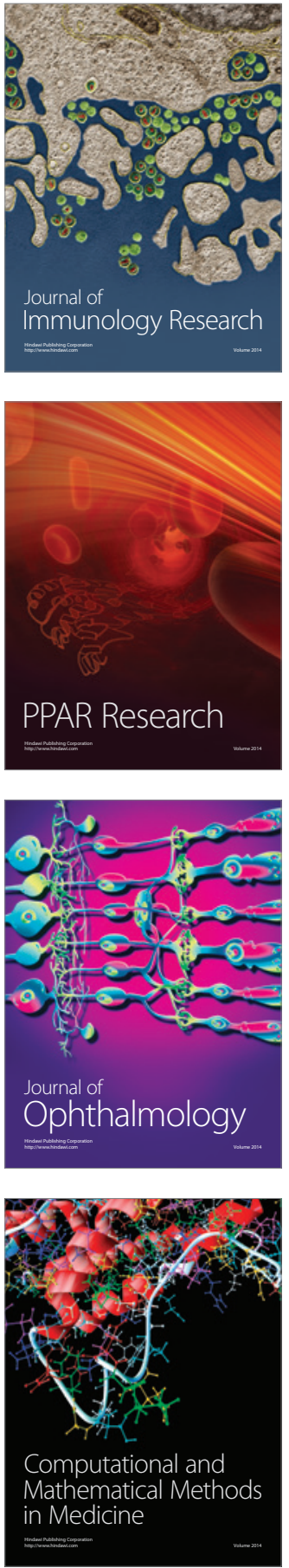

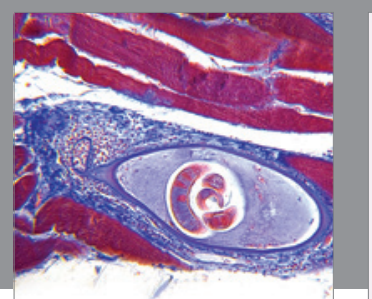

Gastroenterology Research and Practice

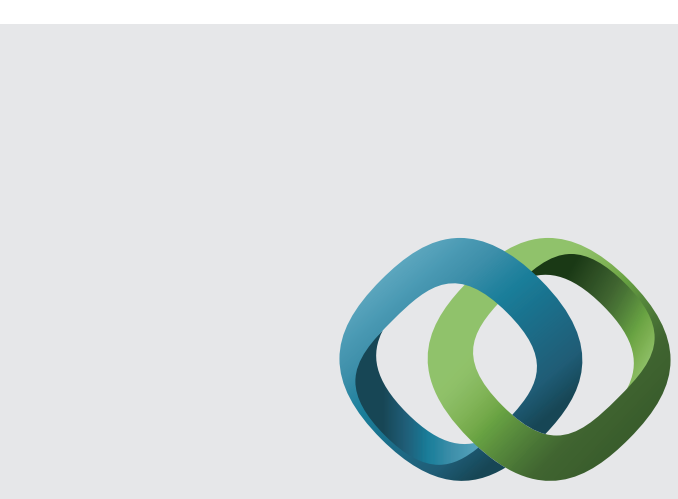

\section{Hindawi}

Submit your manuscripts at

http://www.hindawi.com
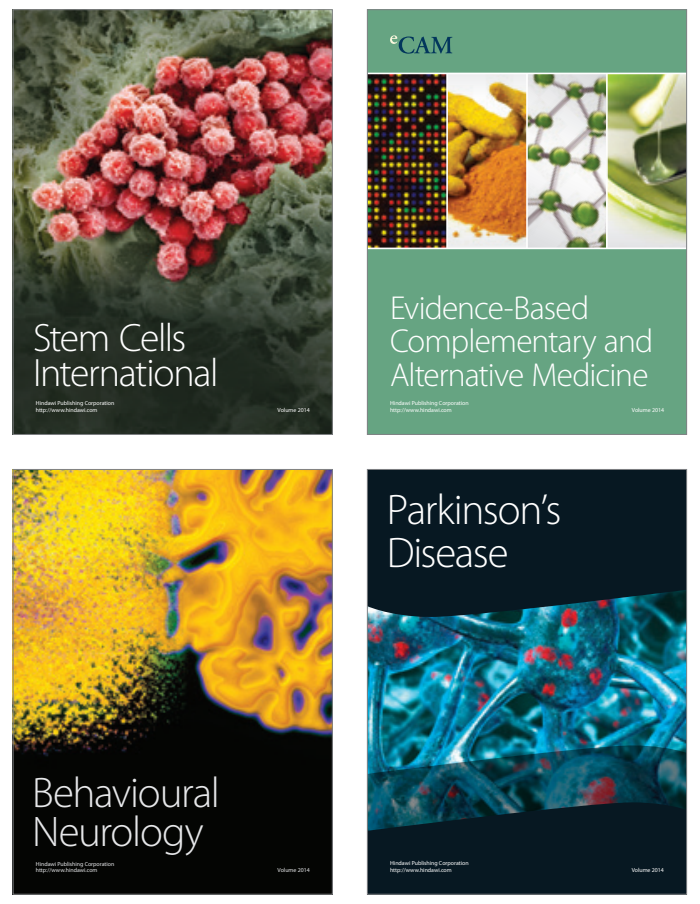
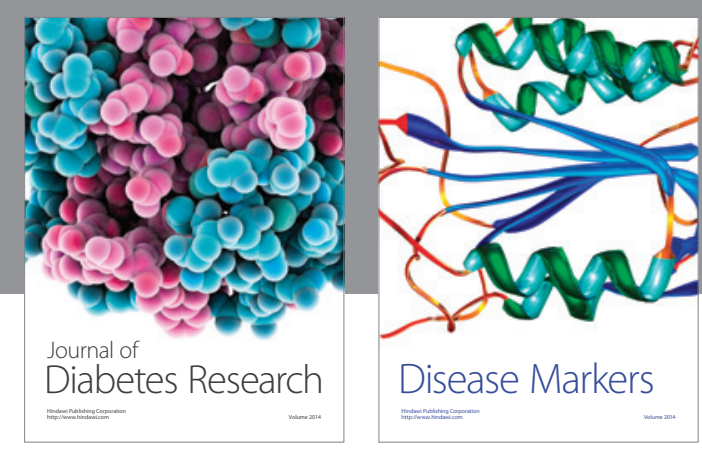

Disease Markers
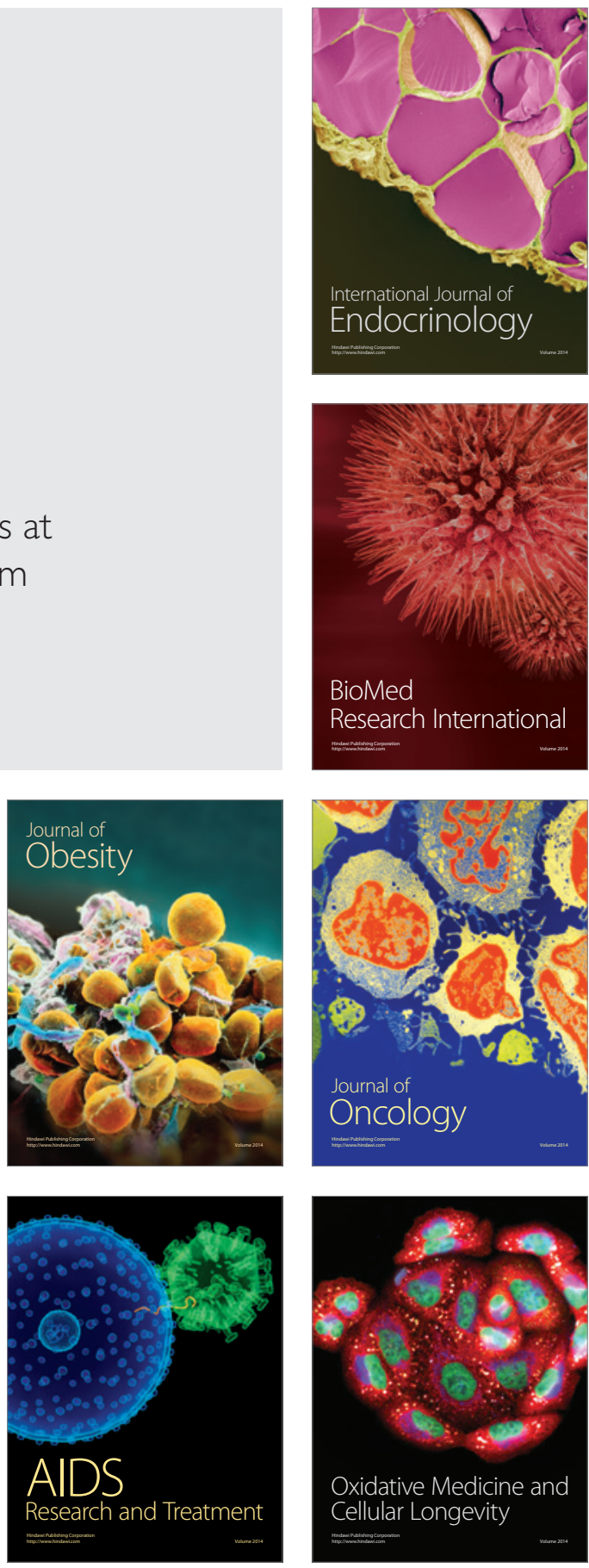